\title{
ON SO-CALLED 'LATERAL [sl': SOME OBSERVATIONS FROM PALATOGRAPHY AND SPECTROGRAPHY
}

A. TRAILL M. LITT. (EDIN.)

African Studies Institute, University of the Witwatersrand, Johannesburg.

\section{SUMMARY}

This paper supplements certain well-known articulatory aspects of signatisms (lisps) with observations derived from spectrography. The five cases studied show widely differing articulations with a relatively invariant acoustic output. A phonological perspective of the problem is argued to be of relevance to therapy.

\section{OPSOMMING}

Hierdie artikel vul sekere bekende artikulatoriese aspekte van sigmatisme (stoot-met-dietong) aan met waarnemings uit die spektrografie. Die vyf gevalle wat bestudeer is, toon grootliks verskillende artikulasietipes met ' $n$ akoestiese uitvoer wat relatief onveranderlik is. Daar word aangevoer dat 'n fonologiese beskouing van die probleem relevant is vir terapie.

In this paper an attempt is made to throw some new light on the familiar problem of lisping (or sigmatism). This will be approached in two complementary directions, firstly phonetically and secondly phonologically. Certain familiar - but possibly not sufficiently widely known - facts about the articulatory aspect of a class of sigmatisms will be reviewed and data from a number of case studies will be interpreted in terms of the traditional classification. The acoustic correlates of these articulations will be presented and their phonological implications assessed. Implications of the findings for therapy will be hinted at.

\section{THE ARTICULATORY ASPECT OF SIGMATISMS}

For the purposes of this paper, certain oral (i.e. non-nasal) sigmatisms will be discussed. These are conventionally classified according to the two phonetic parameters of place of articulation and direction of release of the airstream, leading to classifications varying in detail, completeness and usefulness. For various examples of different classifications the reader is referred to Van Riper and Irwin, ${ }^{13}$ Powers, ${ }^{10}$ Bloomer ${ }^{1}$ and Luchsinger and Amold. ${ }^{8}$ The latter present the most general and explicit classification and provide airflow and palatographic backing to their observations. The oral sigmatisms most frequently described in the literature can be summarised in Table. I.

In addition it is often noted that the lips may be involved in some degree in sigmatism, though precise details of the type of labial articulation are not specified. Regarding the gaps in Table $I$, the writer ventures to suggest that 


\begin{tabular}{|c|c|c|c|}
\hline \multirow[b]{2}{*}{ Release } & \multicolumn{2}{|c|}{ Articulatory Position } & \multirow[b]{2}{*}{ Palatal } \\
\hline & Inter-dental & $\begin{array}{l}\text { 'Anterior' } \\
\text { (dental \& alveolar) }\end{array}$ & \\
\hline Central & i.d. lisp & addental lisp & $\begin{array}{l}\text { palatal/retracted } \\
\text { lisp }\end{array}$ \\
\hline Lateral & i.d. lat. lisp & $\begin{array}{lr}\mathrm{R} / \mathrm{L} \\
\text { bilateral }\end{array}$ ) $\begin{array}{r}\text { lateral } \\
\text { lisp }\end{array}$ & - \\
\hline Pseudo-lateral & - & $\begin{array}{l}\text { Antero-lateral } \\
\text { lisp }\end{array}$ & - \\
\hline
\end{tabular}

TABLE I. A classification of sigmatisms.

only that of the pseudo-lateral palatal reflects an articulatory limitation; the others are apparently 'accidental' gaps. In the remainder of this paper the inter-dental sigmatisms will not be discussed.

Luchsinger and Arnold ${ }^{8}$ (pp. 564-568) define the remaining sigmatisms of Table I as follows:

Addental: . . . the tongue-tip . . . (is pushed) . . . against the posterior surface of the front teeth. . . formation of a medial groove along the tongue-tip becomes impossible, and the air escapes broadly between the teeth in a fan-shaped manner over the anterior portion of the tongue.

Lateral: . . the tongue is elevated on one side more than the other. . . so that air is forced into one cheek pouch where it produces a slurping lisp.

Antero-lateral (lateroflex, pseudo-lateral): . . . the tongue-tip deviates from the midline toward the right or left side and directs the airstream mostly toward the upper canine tooth of the same side.

Palatal: $\quad \ldots$ occurs when the tongue lies too far backward. In that case the fricative noise originates between tongue-tip and hard palate ... The palatal $[\mathrm{s}]$ therefore sounds like a German $[\mathrm{c}]$ or even a $\left[\int\right]$.

These authors' injunction to use precise visual and experimental exploration for the exact differentiation of the different types of sigmatism is worth repeating since faulty or imprecise diagnoses are inimical to adequate therapy. As an example of the subtle differences that can be revealed by palatography, for example, consider the articulatory differences between two cases of antero-lateral lisps for [s] and [ $\left.\int\right]$ given by Luchsinger and Arnold, ${ }^{\mathbf{s}}$ and reproduced as Figure 1 opposite. 


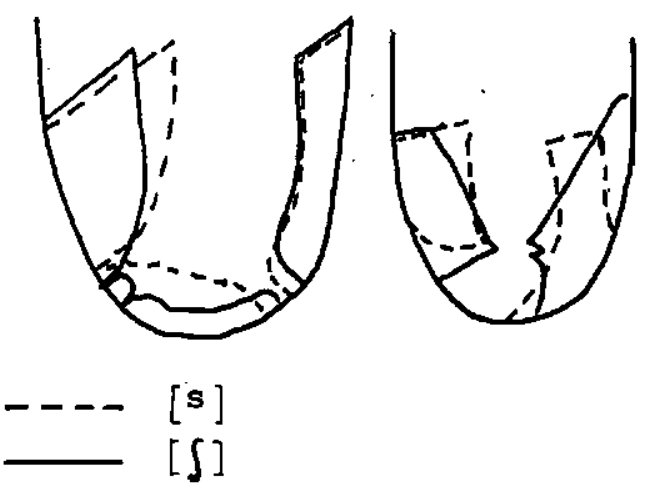

Figure 1. Palatograms of fine detail distinguishing sigmatisms (Luchsinger. and Arnold ${ }^{8}$ ).

If acoustic data were available to supplement the articulatory information provided by the palatograms, a precise and objective classification of the sigmatisms could be given.

I shall now examine palatographic data from five cases of sigmatisms from the Speech and Hearing Clinic of the University of the Witwatersrand. The point of the exercise will be twofold: firstly it will provide a test of the adequacy of the classification of sigmatisms above; secondly it will provide the articulatory facts with which acoustic data can be correlated below. All subjects are English speaking. The shape of the dental arch has been standardised for all cases.

Case 1 Sigmatism affecting /s/, /z/ only. Diagnosed as 'lateral s'

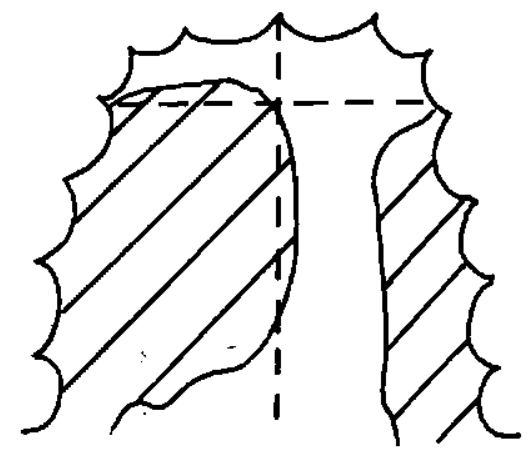

Figure 2. Palatogram for Case 1 [s].

The hatched area in Figure 2 and subsequent palatograms represents the area of articulatory contact between tongue and palate.

The anterior part of the closure is asymmetric, being slightly retracted on the left side. Otherwise this would be the sort of wipe-off one would associate with an alveolar point of articulation. There is extensive and asymmetric con. 
tact from the alveolar ridge posteriorly. The passageway through which the airstream is channelled is a wide groove (or narrow slit) for the greater part of its length, fanning out posteriorly in the palato-velar region. The length of this wide groove is significant, stretching from the palatal to alveolar point of articulation. The groove is situated entirely to the left of the midline of the palate so that the airstream appears to be aimed against the left upper incisor. This articulation deviates from that of a normal [s] in a number of respects: the asymmetry in the anterior point of articulation and the related deviation from the mid-line of the palate of the wider groove; the length of the wide groove; the abnormally wide area of contact between tongue and palate.

For comparison, a typical palatogram for a nomal [s] is given in Figure 3.

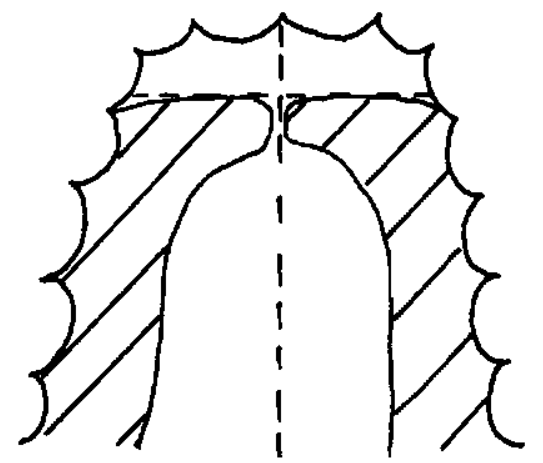

Figure 3. Palatogram for normal [s].

The auditory effect of this sigmatism is something like the blade palatal fricative [c]. On this criterion it would be Luchsinger and Arnold's 8 palatal sigmatism. However, the palatographic data clearly shows that this is not the case; the anterior point of articulation is alveolar, not palatal. This sigmatism is therefore strictly not classifiable in the above classification.

Case 2 Sigmatism affecting $/ \mathrm{s} / / z /, / \int / / 3 /$, and $/ . \int / / \overline{\mathrm{d}} \mathrm{z} /$. Diagnosed as 'lateral s'.

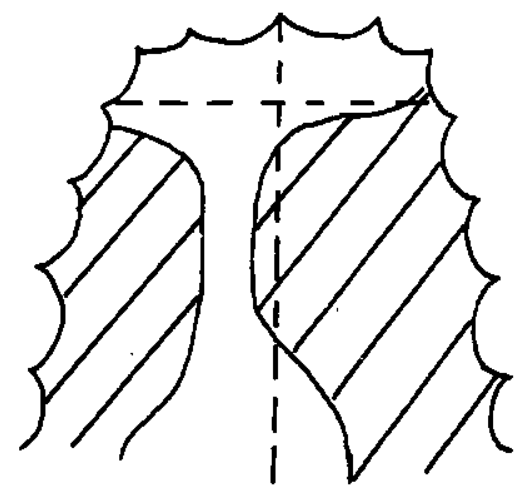

Figure 4. Palatogram for Case 2 [s] and [ $\left.\int\right]$. 
The articulatory details of this sigmatism are the mirror image of those above. The anterior point-of-articulation asymmetry is on the right side and the wide groove is displaced to the right of the midline. Again, the anterior point of articulation is more alveolar than anything else, and the bulk of the airstream appears to be aimed at the (right) upper central incisor. The impressionistic effect is also that of the blade palatal [ç] although, as with the first case, the point of articulation is not straightforwardly palatal.

However, close visual examination as well as attempts to locate the points of exit for airflow reveal something of a fanning of the airstream which is not clear from the palatogram above. In other words air is aimed at the upper lateral incisors as well as the left upper incisor. The articulation involves the blade of the tongue. The sigmatism for $\left[\int\right]$ involves exactly these details but has in addition lip rounding.

Case 3 Sigmatism affecting /s/ / $/$ only. Diagnosed as 'lateral s'.

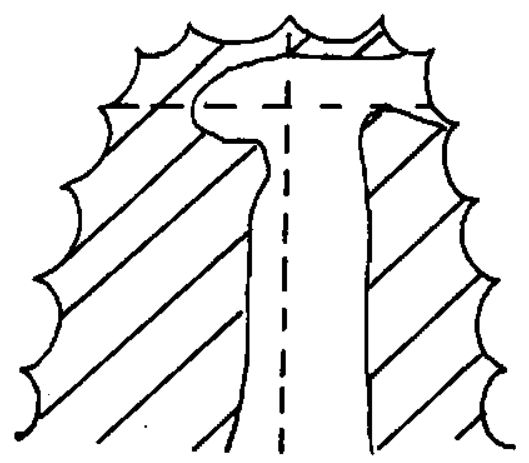

Figure 5. Palatogram for Case 3 [s].

Careful inspection of the palatogram in Figure 5 suggests some lingual contortions. The articulation is in fact achieved by a considerable displacement of the lower jaw to the right, that is to the same side from which the sound is released. The anterior point of occlusion is from the alveolar ridge to the teeth on the left, with the tongue tip in contact with the posterior surface of both upper incisors. However, on the right side the anterior point of closure is alveolar. This extreme asymmetry is achieved by twisting the tip of the tongue to the right so that its left edge has a wide and long contact with both the lateral and front teeth. The right edge of the tongue is therefore brought into a shorter though not exactly narrow contact with the palate from the first primary molar to beyond the second. The point of release is onto the right canine and the first molar. The passageway for the airstream is a slit displaced to the right of the midline for the greater part of its length and lines up with the right upper incisor. However, at the alveolar ridge the passageway extends bilaterally. Release centrally and to the left is blocked by the left anterior closure, but release to the right is'unhindered. The total effect of the articulation is to produce a passageway that looks like a capital $T$, with the stem lying to the right of the midline of the palate. The auditory effect of the articulation could only misleadingly be called that of the lateral fricative 
$[£]$; the point of release of this sigmatism is anterior to that for conventional $[\notin]$ and this no doubt contributes to the peculiar auditory effect.

The deviations from normal [s] are as follows: the left-right asymmetry in the anterior closure; the abnormally wide area of contact between tongue and palate, leading to a slit to the right of the midline of the palate, which is then diverted laterally at the alveolar ridge. In other words, if the right-left asymmetry was removed, and central release effected, the result would be a slit fricative released onto the right upper central incisor.

This sigmatism is clearly a right antero-lateral (or lateroflex or pseudolateral) one in terms of the classification above.

Case 4 Sigmatism affecting /s/. Diagnosed as 'lateral s'.

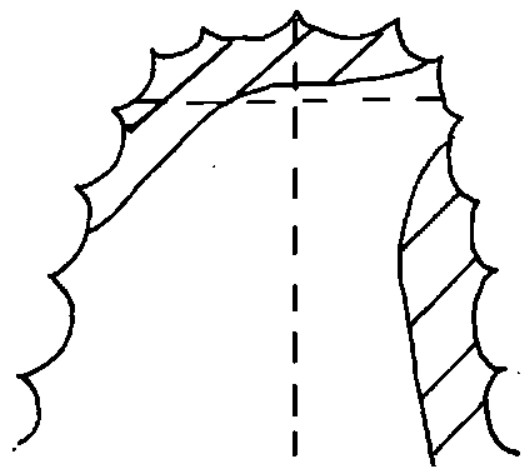

Figure 6. Palatogram for Case 4 [s].

The left to right asymmetry of the anterior point of articulation is again achieved by twisting the tip of the tongue to the right so that complete closure is achieved between the left edge of the tongue along the lateral teeth, and then along the alveolar ridge across to the upper right (primary) lateral incisor. As with Case 3, the right anterior point of articulation is slightly retracted from the alveolar ridge. The point of rele ase is approximately the upper right canine. The passageway through which the airstream is directed is a very short, wide groove adjacent to the canine. The auditory effect is, once again distinct from [£].

This sigmatism is also a clear case of a right anterolateral one but with significant articulatory differences from that of Case 3.

The deviations from [s] are: left-right asymmetry of the anterior points of articulation and a slightly widened groove. Notice, however, that if the asymmetry could be corrected by maintaining the point of articulation and groove but re-positioning the tongue-tip symmetrically round the midline of the palate, no further adjustments would be necessary for an almost perfect reproduction of the articulation for normal [s] (see Figure 3 above). This is because there is a relatively small amount of contact between the edge of the tongue and the palate posterior to the alveolar articulation. In this respect 
Case 4 differs from all those above (as well as Case 5 below) by having a passageway that narrows anteriorly in an abrupt fashion. The other cases, it will be recalled, had either long wide grooves or a long slit resulting from broad and long contact between the edges of the tongue and palate.

Case 5 Sigmatism affecting /s/ / $/$. Diagnosed originally as 'lateral s', but the diagnosis was uncertain at the time of examination.

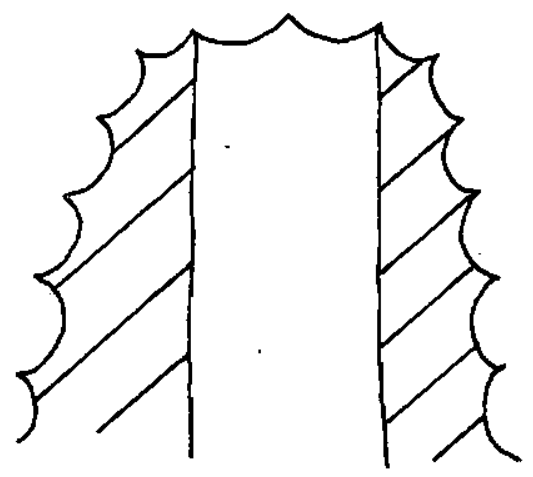

(a)

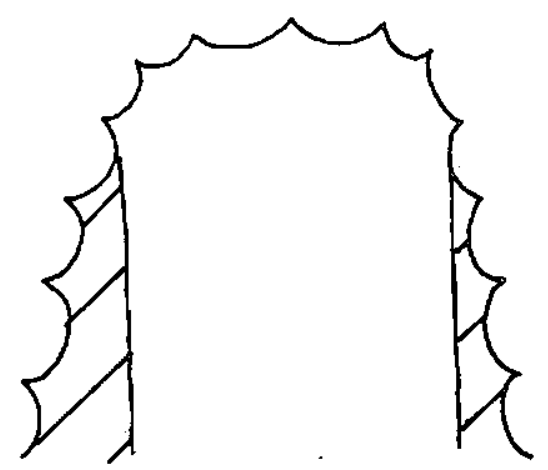

(b)

Figure 7. Palatograms for case 5 [s].

The anterior point of articulation is just behind the upper incisors for (a) and roughly alveolar for (b). The striking point about the articulations is the width of the passageway through which the airstream flows. In (a) it reaches the primary upper lateral incisors while in (b) it stretches between the canines. In (a) there is naturally more contact between tongue and palate than for (b). However, this sigmatism involves a double articulation, the oral one above and a labial one shown in Figure 8 below.

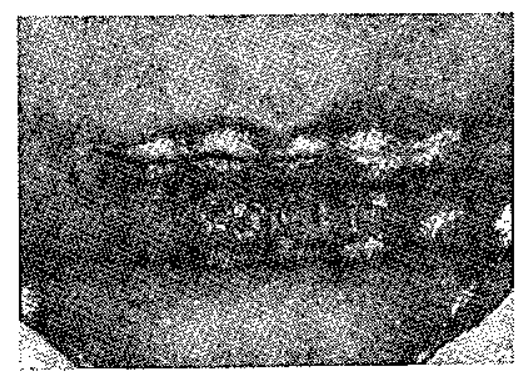

Figure 8. The labial component of sigmatism of Case 5 .

When the lower lip is withdrawn during a prolonged articulation as in Figure 9 next page, the extremely anterior placement of the tongue-tip relative to the upper incisors can be seen, as well as the slit articulation shown in the palatogram in Figure 7 above. 


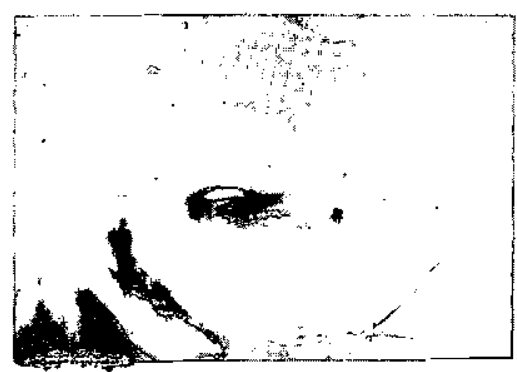

Figure 9. Removal of the labial articulation during the production of a prolonged $[s]$ by Case 5 .

The auditory impression given by this articulation is that of the so-called whistling double fricative [0]. When the labial articulation is disturbed as in Figure 9 above the auditory impression is that of the slit fricative [rir], although in one case the point of articulation is anterior to the conventional alveolar one for $[\dot{i}]$ and there is clearly more of the lateral part of the tongue involved.

The articulation is deviant firstly in the slit rather than groove articulation and the fact that the slit, although symmetrical along the midline of the palate is unvaryingly wide along its entire length. The anterior point of articulation is too advanced for an alveolar consonant in one case. Finally, the labial com: ponent is gratuitous in the normal articulation.

This articulation does not have a strict counterpart in the classification above. While its anterior articulation is possibly addental in the one case it is alveolar in the other and there is no fan-shaped passage for release of the airst ream. The intrusion of a labial articulation in sigmatisms is noted in traditional treatments, although in this case the contribution of this additional articulation is specifically a bilabial fricative, a possibility not explicitly discussed.

With the exception of Case 5, all the above sigmatisms involve a significant distortion of the articulation of the midline of the tongue relative to the midline of the palate, a fact documented clearly by McGlore and Profitt ${ }^{9}$ whose conclusions were derived from strain gauge measurements. Only Case 5 has no such deviation, but, significantly only Case 5 has a labial articulation as well as the oral one. McGlore and Profitt ${ }^{9}$ point out that the normal tendency to bilateral asymmetry in tongue pressure is exaggerated and distorted in the cases of lispers. They attribute this to . . . poor co-ordination of tongue movements. Another articulatory characteristic to emerge from the above palatograms is the general failure of the subjects to achieve the correct amount of contact between the sides of the tongue and the palate and teeth, a problem which has as its immediate effect an ill-proportioned passageway through which the airstream is channelled. In some cases it results in a wide groove incorrectly placed, in others a slit and in others an anterolateral deviation. Only in Case 4 is there something approaching a correctly dimensioned narrowing but this has been rotated to the right and is therefore wrongly positioned.

A question of considerable interest for both traditional articulatory phonetic classification and the accurate description of the sigmatisms above, arises 
when one attempts to describe their place of articulation. For consonants, place of articulation is generally assigned to the point or points of maximum constriction in the supraglottal vocal tract (velic closures do not count). The question is to what extent this criterion is applicable in Cases $1-5$.

Case 5 is straightforward and represents a double articulation bilabial and dental in one case and bilabial and alveolar in the other, these labels identifying the two points of maximum constriction. (That these divergent articulations represent a single phonological entity is, of course, not so straightforward.)

Case 4 is problematic: We have referred to the direction of release of the airstream as antero-lateral. The point of maximum constriction is clearly opposite the right lateral incisor and thus in the vicinity of the alveolar ridge. The fact that there is contact between the edge of the tongue and the front teeth, that is, the presence of dental articulation, seems to be only a mechanical consequence of the distortion of the midline of the tongue towards the right. In a peculiar sense, therefore, Case 4 has a tip alveolar articulation. Notice therefore, how inappropriate the conventional label 'lateral' is for this articulation. Whereas lateral segments like $[\Varangle \ddagger \kappa]$ are classified as dental. alveolar and palatal respectively, with the airstream passing out over the edge of the tongue, in Case 4 , the airstream passes along the centre of the tongue. The latter observation applies to Case 3 as well, though, as noted, this case differs in other respects from Case 4.

The point-of-articulation problem presented by Case 3 is that the slit along which the airstream passes does not have any obvious point of maximum constriction so far as its lingual articulation is concerned. However, the slit is abruptly constricted by the right lateral incisor, again in the vicinity of the alveolar ridge. This poses a dilemma: because of the tongue's deviation to the right the articulation is dental but alveolar, a situation which traditional phonetics is not able to resolve adequately.

Cases 2 and 1 both present the problem that although they both involve an anterior point of articulation that is alveolar, the point of maximum constriction is not confined to that point. In both cases the wide groove stretches from a palatal to an (asymmetric) alveolar point of articulation without altering its dimension significantly. Thus the grooves are not only uniform, they are extremely long. To give an approximate but clearer idea of the length of these grooves compare the section profiles next page for [s] and the sigmatisms under discussion. The profile for [s] is from Heinz and Stevens, ${ }^{6}$ the others are constructions based on the palatograms in Figures 2 and 3.

From a traditional articulatory point of view, the point of articulation for the two sigmatisms is indeterminate; it is thoroughly abnormal. Notice that the traditional secondary articulation of palatalisation is an inappropriate label for Cases 1 and 2 because of the degree and extent of the constriction. A more revealing characterisation of this sort of articulation can be provided by examining its acoustic effect, a point to which we turn below.

For the reader who is impatient to leam what the relevance is of this excur. sion into fine articulatory phonetic detail, it should be pointed out that it is the necessary groundwork for later conclusions of a phonological nature. 


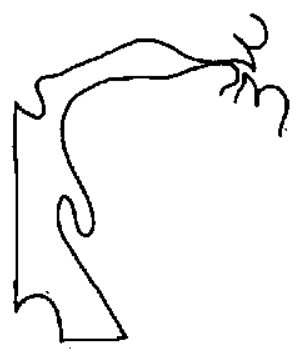

[s]

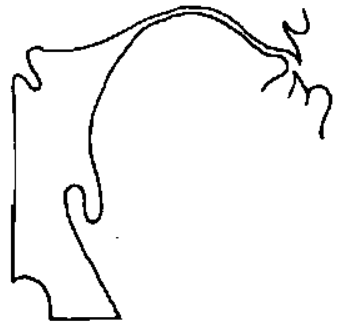

Case 1 (approximate)

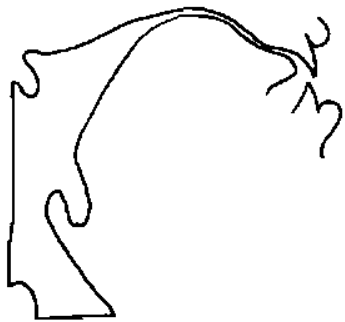

Case 2 (approximate)

Figure 10. Section profiles for normal [s] and two sigmatisms.

When the phonological status of the sigmatisms is assessed it will have to be done against a well-founded set of articulatory and/or acoustic features. The importance of establishing this set in the precisest terms possible will become most apparent when the fundamental question of degree of deviation is raised.

\section{THE ACOUSTIC ASPECT OF SIGMATISMS}

This section will be confined to examining only certain aspects of the acoustic effect of the above articulations with a view mainly to supplement the articulatory descriptions so that later phonological conclusions will be adequately grounded.

The production and acoustic effect of turbulent airflow in the vocal tract has been closely studied for example by Heinz and Stevens, ${ }^{6}$ Stevens ${ }^{11,12}$ and Fant. ${ }^{4}$ A number of factors are considered in the analysis of articulations that result in turbulence. These are the length of the cavities posterior and anterior to the constriction, the length of the constriction, the cross-sectional area of the constriction and, in Stevens' terms, the degree of acoustic coupling between the two cavities. The interaction of these factors and their acoustic output can be calculated in a precise manner from an idealised model of a constricted vocal tract, yielding results which fit well with data derived from the study of actual vocal tracts (Stevens ${ }^{12}$ ). The applicability of these findings to the cases under discussion is confounded by the lack of data on cavity sizes for each case, as well as the unknown effects of the abnormal articulatory configurations, in particular the irregular constrictions and cavities. It is thus not possible even to estimate a valid correcting factor in order to accommodate Stevens' predictions. Therefore the few interpretations made below that draw on these predictions should be judged against the reservations expressed. It should be noted, however, that the main conclusion I wish to draw from the acoustic data is not affected.

Figures $11-16$ are broad band spectrograms of English words recorded by Cases $1-5$, illustrating the various sigmatisms. Table II presents an analysis of these and other spectrograms in terms of the upper and lower limits of the 


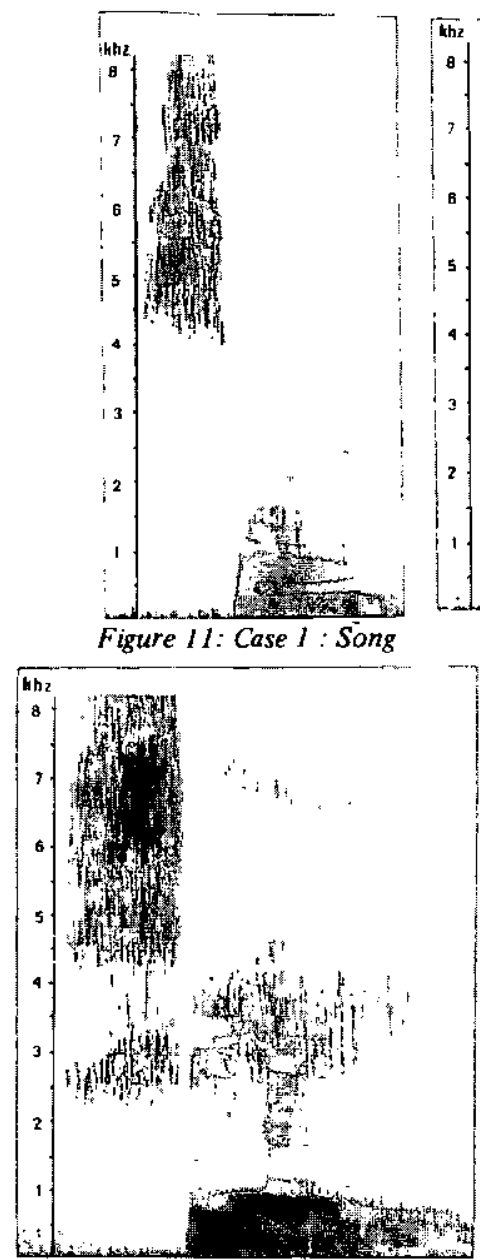

Figure 13: Case 3 : Sand

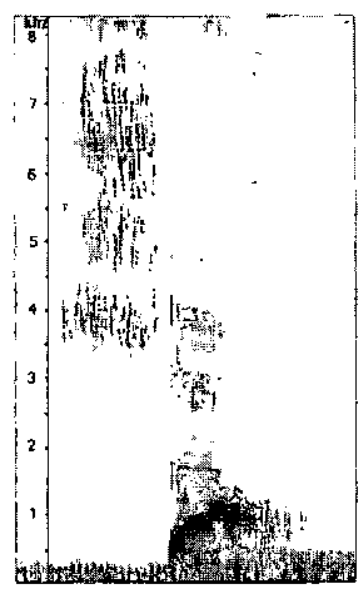

Figure 15: Case 4 : Song

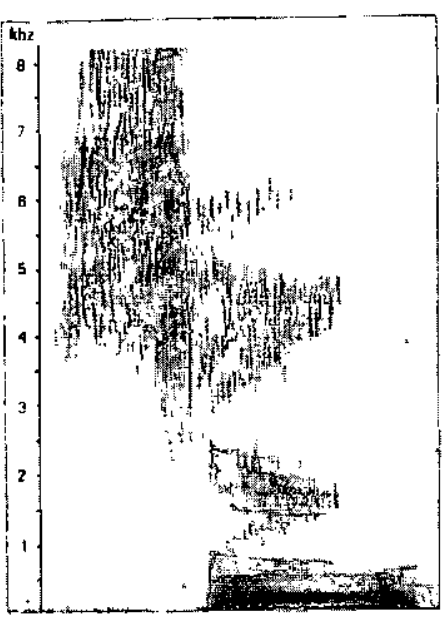

Figure 12: Cose 2 : Song

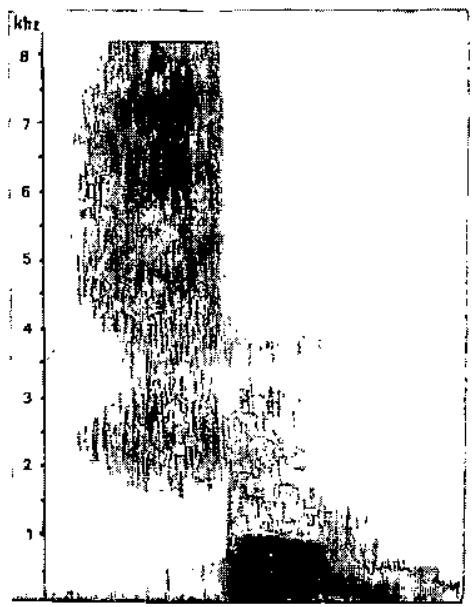

Figure 14: Case 3 : Song

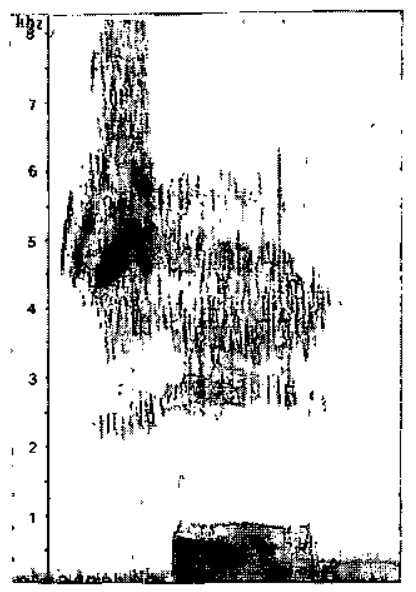

Figure 16: Cose 5 : Sand 
fricative noise in the spectrum as well as the major spectral peak(s) in this range. The latter were derived from a section taken at a point immediately prior to the release of the constriction and the onset of the vocalic segment. Figures in brackets refer to a section taken at a point about $8 \mathrm{~m}$. secs earlier in the segment. Underlined figures represent the greatest peak. The average given under the column 'Range' is the averaged lowest frequency of the range. For comparison, averaged figures for 2 normal children of comparable age to the subjects are included in Table II.

The striking feature about all these sigmatisms is that their spectral energy is concentrated relatively high and there is most frequently no energy at lower frequencies. This characteristic places the sigmatisms firmly in the same category as normal $[s]$ and $[\Omega]$, the very segments of which they are deviant renderings. If one considers the range of articulations that underlie this acoustic unity, this is a noteworthy feature. It shows that a number of articulatory positions and adjustments are compatible with the single acoustic feature of energy at relatively high frequencies. This property is lacking in the other English fricatives [ $f \vee \theta$ ] ]. The property has been labelled stridency (e.g. Halle ${ }^{5}$ ) or sibilance (Laaefoged 7 ). Stevens 12 proposes that the basis for the distinction between the two classes of fricative is the presence in the strident set of a . . . coincidence between a pair of resonances . . .; that for particular points of constriction . . . corresponding to two coincident resonances, a maximum is obtained in sound output and the resonant peak is relatively insensitive to small perturbations in the positions of the constriction. There exist, as it were, certain discrete or quantal constriction positions (places of articulation) for sound production. The articulatory and acoustic details of the sigmatisms may be interpreted in the light of these quotations as showing that none of them involves a transgression of the optimisation point for the production of a particular acoustic result. This has been achieved articulatorily by directing the turbulent airflow at roughly right-angles onto the upper teeth or incisors which therefore provide a sharp obstacle and greater noisiness. It is known that quite considerable differences exist between languages and within a language for acceptable amounts of tongue-palate contact in the production of normal [s] and [ $\left.\int\right]$ (Dieth ${ }^{3}$ ), but it is clear that none of the above sigmatisms can be considered to fall within the limits of this normal variation because of the excessive amount of contact and, for some cases, grossly asymmetric contact. It is likely that peculiar features of the abnormal constrictions themselves contribute to the particular effect, but this point will not be pursued in any detail here.

A few observations on each case follow.

\section{Case 1}

There is a clear concentration of energy above $\sim 3,6 \mathrm{KHz}$ and none below it. The spectrum is however flat, without any prominent major peak. Generally the greater energy is located around $6,0 \mathrm{KHz}$ but it falls away only very gradually around this point. The suggestion of an upward bending where $F 2$ is expected, in the spectrogram for song, is consistent with a palatal point of articulation, but the location in the section of a peak of energy as high as 6 $\mathrm{KHz}$ suggests a more anterior point of articulation. 


\begin{tabular}{|c|c|c|}
\hline Sigmatism & Range $(\mathrm{KHz})$ to 8,1 & Major Peaks(s) (KHz) \\
\hline Case 1 'palatal s' & $\begin{array}{c}4,0 \\
3,6 \\
4,0 \\
4,1 \\
\text { (Av. 3,19) }\end{array}$ & $\begin{array}{l}5,5 \text { to } 7,0(\underline{6,0}) \\
4,5 \text { to } 7,0(\underline{5,25)}) \\
5,25 \text { to } 6,5(6,0) \\
4,75 \text { to } 6,25(\underline{6,0}) \\
\quad(A v .5,8)\end{array}$ \\
\hline Case 2 'palatal s' & $\begin{array}{c}1,75 \\
(4,25) \\
2,3 \\
(3,25) \\
3,50 \\
3,55 \\
\text { (Av. } 3,1)\end{array}$ & 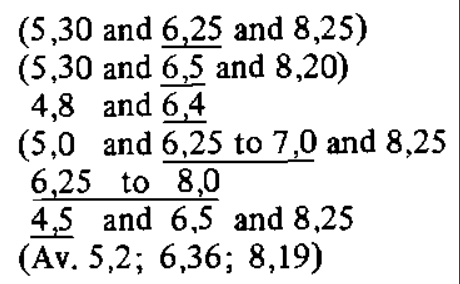 \\
\hline 'palatal $f$ ' & $\begin{array}{c}2,5 \\
2,25 \\
.60 \\
(3,50) \\
\text { (Av. } 2,87)\end{array}$ & $\begin{array}{l}5,0 \text { and } 6,5 \text { and } 8,0 \\
4,25 \text { and } \frac{6,4}{4} \text { and } 8,0 \\
4,0 \text { to } 5,0 \text { and } 6,3 \text { and } 7,5 \\
(4,5 \text { and } 6,25 \text { and } 7,75) \\
\text { (Av. } 4,56-6,36 ; 7,81)\end{array}$ \\
\hline Case 3 'antero-lateral s' & $\begin{array}{c}3,60 \\
(2,00) \\
2,40 \\
(1,75) \\
\text { (Av. } 2,44)\end{array}$ & $\begin{array}{l}4,9 \text { and } 6,25 \text { and } 7,5 \\
\left(2,6 \text { and } \frac{4,25}{5,1} \text { and } 6,0 \text { to } 7,5\right) \\
3,4 \text { and } 6,6 \\
(3,0 \text { and } 5,25 \text { and } 6,5 \text { to } 7,0) \\
(\text { Av } 3,5 ; 5,21 ; 7,00)\end{array}$ \\
\hline Case 4 'antero-lateral s' & $\begin{array}{c}3,6 \\
3,8 \\
(3,7) \\
3,8 \\
(\text { Av. } 3,7)\end{array}$ & $\begin{array}{l}4,1 \text { and } 6,0 \text { to } 7,25 \\
4,1 \text { and } \frac{4,1 \text { and } 7,4}{(4,25 \text { and } 5,5 \text { and } 7,1)} \\
4,4 \text { and } 6,0 \text { and } 7,0 \text { to } 7,6 \\
(\text { Av. } 4,21-5,80 ; 7,26)\end{array}$ \\
\hline $\begin{array}{r}\text { Case 5 (a) 'double s' } \\
\text { in words } \\
\text { (b) 'double s' } \\
\text { in isolation }\end{array}$ & $\begin{array}{c}1,0 \\
0,75 \\
0,60 \\
(2,4) \\
\text { (Av. } 1,19 \text { ) } \\
3,0 \\
2,75 \\
\text { (Av. } 2,87)\end{array}$ & $\begin{array}{l}\frac{5,0}{5,0} \\
\frac{5,1}{5,0} \\
(\overline{A v}, 5,0) \\
\frac{4,8}{4,4} \text { and } 6,4 \text { and } 7,7 \\
(\overline{A v} .4,6 ; 6,4 ; 7,7)\end{array}$ \\
\hline 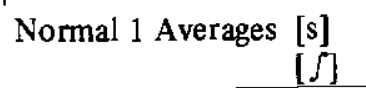 & $\begin{array}{l}4,0 \\
2,5\end{array}$ & $\begin{array}{lll}5,27 & 7,22 & \\
3,26 & 6,15 & 7,81 \\
\end{array}$ \\
\hline $\begin{array}{r}\text { Normal 2 Averages [s] } \\
{[\delta]}\end{array}$ & $\begin{array}{l}4,0 \\
2,5\end{array}$ & $\begin{array}{ll}6,25 & 8,50 \\
3,60 & 7,50\end{array}$ \\
\hline
\end{tabular}

TABLE II. An analysis of the range and concentration of spectral noise during the production of various sigmatisms. 
The latter observation is consistent with the palatographic evidence, the former with the possibility mooted above that a point more posterior within the constriction is contributing to the production. Whatever the case may be, the flat envelope is not normal for sibilance on the one hand, but its high location is, on the other. This case's productions of $\left[\int\right]$ are thoroughly normal with a lower peak corresponding to the coincidence of $\mathrm{F} 3$ and $\mathrm{F} 4$, and a cut off point at $2 \mathrm{KHz}$.

\section{Case 2}

Although the palatogram for this case is the mirror image of that for Case 1, there are a number of differences. Firstly, both [s] and [ $S$ ] are affected; secondly, Case 2 has much more clearly defined peaks of energy in the sigmatisms; thirdly, Case 2's articulation often shifts just prior to release of the consonant, with the effect of spreading the spectrum to lower frequencies of very weak intensity. This latter point is clearly seen by examining the figures in Table II for the sections taken at a point before the shift is evident acoustically.

The acoustic difference between the two sigmatisms involves firstly a generally higher intensity for the sigmatism of [s] as well as a slightly wider envelope for the sigmatism of $\left[\int\right](2,87 \mathrm{KHz}$ vs. $3,1 \mathrm{KHz}$ for the [s] sigmatism) and a lower peak of energy situated at $\sim 4,56 \mathrm{KHz}$ for $[f]$ (ch. $5,20 \mathrm{KHz}$ for $[\mathrm{s}]$ ). These differences can be attributed solely to the effect of the lip-rounding found only in the [ $\left.\int\right]$ sigmatism. The addition of this anterior cavity serves to lower the resonances slightly. However the differences achieved in this way do not approximate normal differences between $[\delta]$ and [s] and in fact, the auditory impression is mostly of identity. If one mechanically manipulates the lips so as to prevent the formation of a labial resonating cavity, no difference exists. So far as point of articulation is concerned, this is indeterminate for traditional categories because F2 bending and F4 and F5 amplification point to the possibility of a complex source for the turbulence. This evidence suggests that use of the label 'palatal' distorts both the articulatory and acoustic reality. This accords with the palatographic evidence. Both sigmatisms qualify as sibilants with a frequency range beginning very high up. It is of interest to note that the data for Case 2 were collected on separate occasions about eight months apart and considerable differences in intensity are found between intensity levels for the $\left[\int\right]$ sigmatism, with the later sample showing less intensity than the first one. Although this will not be pursued here, this sort of comparison is highly suggestive for longitudinal assessment of treatment.

\section{Case 3}

Compared with the spectrum for normal sibilants and for all the sigmatisms except that of Case 5. Case 3's spectrum is wide, with energy as low as 1,75 $\mathrm{KHz}$. There are clear peaks of energy however and generally two of these are located at $\sim 5,21 \mathrm{KHz}$ and $\sim 7,00 \mathrm{KHz}$. The location of a peak of energy at $\sim 3,30 \mathrm{KHz}$, however, is abnormal for [s] and is undoubtedly attributable to the peculiarities of the airway and its anterior deviation. This lower peak would be expected with normal [S], but auditorily, its effect is balanced by 
the high-frequency peaks consistent with [s]. Despite the abnormality noted, this sigmatism clearly meets all the acoustic requirements for classification as a sibilant. The balance between [s]- like and [ $\left.\int\right]$ - like acoustic features relies on the location of the energy peaks in the spectrum for the fricative. In so far as the data are clear, Stevens' criteria would suggest a balance has been achieved in Fig 13 but that [ $\mathrm{S}$ ]- like properties predominate in Fig. 14. Unfortunately no data is available on this case's normal [ $\left.\int\right]$.

\section{Case 4}

This sigmatism involves peaks of low intensity at $\sim 4,21 \mathrm{KHz}, 5,80 \mathrm{KHz}$ and $7,26 \mathrm{KHz}$. Like the previous case, this suggests a combination of [s]- like and [ $\left.\int\right]$ - like characteristics and depending on the intensity of the lower peak $v$. the higher peaks, one or other will predominate. For instance in Fig. 15 where the section shows no clear resolution of the higher frequencies [s]- like amplifications are missing in the transition to the vowel, but the peak found at $\sim 4,0$ $\mathrm{KHz}$ is amplified in to $\mathrm{F} 3$ and $\mathrm{F} 4$ suggesting [ $\int$ ]- like properties; other spectrograms, however, display [s]-like properties. This may be due to inconsistent articulations, but it could also reflect peculiar effects of the orientation and shape of the constriction. Once again, traditional articulatory labels fail to provide an accurate categorisation.

\section{Case 5}

The presence of low-frequency noise is due to the turbulence generated at the lips. In addition, this constriction evidently serves to amplify frequencies with great intensity and consistency around $5,0 \mathrm{KHz}$. Removing the labial constriction removes certain low-intensity noise probably generated by the lips. Emerging from $5 \mathrm{KHz}$ in the transition to the vowel are F4 and F5 which in Stevens' terms points to post dental constriction. This is of interest because it suggests a narrowing there that is not visible either from the palatograms or the picture of the position of the tongue-tip relative to the upper incisors (Figure 9). One may speculate that the deep and wide groove evident in that picture extends only a short way posteriorly, possibly to the alveolar ridge, where a shallower constriction lies. Although this is a double fricative with labial and dentalalveolar points of articulation and a wide groove, it is evident from the acoustic data that traditional articulatory categories do not really help to elucidate the nature of the sigmatism. It is noteworthy that this sigmatism qualifies as a sibilant like all the cases surveyed. The strongly focused, high location of an exceptionally high peak of energy is the mark of a sibilant according to the definition used in this paper, and although there is low-frequency-lowintensity noise it is effectively neutralised from a linguistic point of view by the other feature.

The acoustic properties of [ $\left.\int\right]$ for this case are normal with clear spectral peaks at $2,5 \mathrm{KHz}$ and $5,0 \mathrm{KHz}$. A certain amount of low-intensity noise at all the lower frequencies of the spectrum points strongly to the lips being involved in this articulation, although this was not noticed during the recording session.

\section{THE PHONOLOGICAL ASPECT OF THE SIGMATISMS}

In this section an attempt will be made to assess the functional significance of 
the sigmatisms for the phonological system which underlies them. The point to be emphasised is that all the articulatory and acoustic phonetic data examined are of little interest in their own right. Their true value, strictly speaking, can only be determined by examining how they are structured phonologically. To put it differently, as linguistic sounds, these sigmatisms must be seen as expressing some phonological contrast, and they lose all significance if treated outside such a context. The only way to arrive at an accurate assessment of their severity in the sense of their disruptive effect on the phonological system, is to view them in their proper linguistic context. This in turn will lead to implications for a controlled therapy routine.

The English fricative series is as follows:

\begin{tabular}{|c|c|c|c|}
\hline $\mathbf{f}$ & $\theta$ & $\mathbf{s}$ & $\boldsymbol{f}$ \\
\cline { 1 - 2 } $\mathbf{v}$ & gे & $\mathbf{z}$ & 3 \\
\hline
\end{tabular}

The system of oppositions that structure the series involves the presence or absence of voice and articulatory position. There is, however, the need for an additional feature in order to provide a natural explanation for the distribution of the plural and 3 rd person singular allomorphs $/-\dot{z} z /$ and $/-z \sim-s /$ :

$\begin{array}{lrrrr}\text { Safe }-\mathrm{s} & \text { path }-\mathrm{s} & \text { kiss }-3 \mathrm{z} & \text { fish }-\mathbf{3 z} & \text { latch }-3 z \\ \text { cave }-\mathrm{z} & \text { tithe }-\mathrm{z} & \text { fizz }-3 \mathrm{z} & \text { garage }-3 z & \text { badge }-3 z\end{array}$

For this rule, English treats the class of final consonants $/ \mathrm{s} z \int 3 \mathrm{t} \int \mathrm{d} 3 /$ as a natural one; they all take the $/-3 z$ / allomorph. In order to explain this, one searches for a single feature that they all share in common which is lacking in the complementary class of / $\mathrm{f} v \theta$ o /. The feature is of course 'sibilance' (or stridency) and it has its phonetic basis in articulatory and acoustic details that have been mentioned though it is actually defined in acoustic terms only (Ladefoged $^{7}$ ). To express this in current terms, each fricative represents a bundle of distinctive features, the relevant ones of which can be displayed as follows:

\begin{tabular}{|l|c|c|c|c||c|c|c|c||}
\cline { 3 - 8 } \multicolumn{1}{c|}{} & $\mathrm{f}$ & $\mathrm{v}$ & $\theta$ & d & $\mathrm{s}$ & $\mathrm{z}$ & $\mathrm{f}$ & 3 \\
\hline voice & - & + & - & + & - & + & - & + \\
\hline sibilance & - & - & - & - & + & + & + & + \\
\hline anterior & + & + & + & + & + & + & - &, \\
\hline
\end{tabular}

The boxed-in fricatives are those involved in the sigmatisms discussed above and we may now ask how these so-called articulatory defects disrupt the above system. With the exception of Case 2 , the answer is not at all. Cases $1,3,4,5$, show that despite widely different articulatory details, the sigmatisms are sibilants; the voice and position features are not affected. Case 2 differs in the latter respect; the bundles $<+$ sibilant \pm anterior $>$ have been collapsed to a single sibilant using the tongue blade. That is, there is no positional contrast 
involving the feature $<+$ sibilant $>$ for Case 2 . Instead, labialisation is the surrogate for the pair of features

$$
\left[\begin{array}{l}
- \text { anterior } \\
+ \text { labial }
\end{array}\right]
$$

In other words, Case 2 has restructured the physical instantiation of the sibilant fricatives. The question is whether this has been successful and, as noted above, the answer is that it has not. Clearly, the difference between the normal expression of $/ \mathrm{s} /$ and $/ \mathrm{S} /$ cannot be achieved through lip rounding alone; a positional shift is necessary in order to create a larger anterior cavity for the particular resonances associated with normal [S]. Case 2 therefore disrupts the system of fricatives at a systemic level and must to that extent be regarded as the most serious of the cases presented. This disruption is reflected below:

\begin{tabular}{|l|c|c|c|c|c|c|}
\cline { 2 - 7 } \multicolumn{1}{c|}{} & $\mathbf{f}$ & $\mathbf{v}$ & $\theta$ & ठे & $\mathbf{C}$ & J \\
\cline { 2 - 7 } \cline { 4 - 7 } Voice & - & + & - & + & - & + \\
\hline Sibilant & - & - & - & - & + & + \\
\hline Anterior & + & + & + & + & - & - \\
\hline Coronal & - & - & + & + & - & - \\
\hline
\end{tabular}

(The symbols $\mathrm{C}$ and $\mathrm{J}$ cover normal $\left[\mathrm{s} \int_{\mathrm{d}}\right]$ and $\left[\begin{array}{ll}\mathrm{z} & \mathbf{g}\end{array}\right]$ respectively)

It was noted above that the feature 'sibilance' is customarily given a clearly acoustic definition and I would suggest that in a sense the correctness of this emphasis is borne out by the fact that each case has managed to preserve the acoustic feature of sibilance under quite different articulatory configurations. This points strongly to the reality of the feature as the target in the child's acquisition of English fricative contrasts, and is further confirmation of the entrenched or resistant nature of the feature in various disorders (Cairns and Williams ${ }^{2}$ ).

Case 2 can be seen therefore to have a truly linguistic problem as against what are probably best described as the cosmetic problems of the other cases. These cosmetic problems are attributable to deviations from the norm of fine acoustic detail which arise from various kinds of articulatory distortion. Put differ: ently it is clear that Cases $1,3,4$ and 5 completely satisfy the requirements of English fricatives at the phonological and phonetic level and to that extent they must be regarded as normal. It is true that the abnormalities which lead these cases to be diagnosed in the first place as having a speech defect are indeed expressed in phonetic substance, but it must be understood that these phonetic deviations are not sufficient to disrupt the linguistic system and, in a sense, are therefore most superficial. Their linguistic triviality may in fact partly explain why sigmatisms are so resistant to therapy: at a certain level, there is no reason to change!

However, the fact is that such cases nevertheless require therapy and one may ask whether the observations made in this paper would favour any particular programme. It seems they do. They suggest that the articulatory distortions themselves should be the explicit and direct focus for therapy, rather than 
auditory feedback. The basis for this emphasis is that the cosmetic distortions derive directly from the articulatory facts of abnormal constrictions and ab. normal orientations. At an auditory level the output of these articulatory configurations is fully acceptable linguistically and therefore likely to be highly resistant to change. It would be reasonable instead to aim directly at articulatory adjustments which would not only preserve the linguistically necessary acoustic output, but at the same time remove the fine but offensive acoustic deviations. By way of a practical suggestion, one may suggest that normal [s] could be 'grafted on' to the release of the voiceless alveolar stop since, firstly, the sides of the tongue would be normally orientated, secondly, release would be central, and thirdly the friction associated with an aspirated release could be transformed into a linguistically and cosmetically acceptable [s]. Initial [s] could be introduced in this way by juxtaposing words with initial [s] after words with final [th]. This sort of approach could establish the correct kinaesthetic feedback, and indeed one would expect just this in terms of the motor theory of speech perception. Case 2, obviously requires an approach which takes into account the linguistic and any cosmetic deviations, but it would seem that this could also be done through an articulatory programme.

\section{REFERENCES}

1. Bloomer, H. H. (1971): Speech defects associated with dental malocclusions and related abnormalities. In Handbook of Speech Pathology and Audiology, Travis L. E., (Ed.). New York: Appleton-Century Crofts.

2. Cairns, H.S. and Williams, F. (1972): An analysis of the substitution errors of a group of standard English-speaking children. J. Speech Hear. Res., 15, 811-820.

3. Dieth, E. (1950): Vademekum der Phonetik. Bern: A. Frank.

4. Fant, G. (1970): Acoustic Theory of Speech Production. The Hague: Mouton.

5. Halle, M. (1959): The Sound Pattern of Russian. Gravenhage: Mouton.

6. Heinz, J.M. and Stevens, K: N. (1961): On the properties of voiceless fricative consonants. J. Acoust. Soc. Amer. 33, 589-596.

7. Ladefoged, P. (1971): Preliminaries to Linguistic Phonetics. University of Chicago Press.

8. Luchsinger, R., and Arnold, G. E. (1965): Voice, Speech, Language: Clinical Communicology: Its physiology and pathology. Belmont: Wads= worth.

9. McGlore, R. E. and Profitt, W. R. (1973): Patterns of tongue contact in normal and lisping speakers. J. Speech Hear. Res. 16, 456-473.

10. Powers, M. H. (1971): Functional disorders of articulation - symptomatology and etiology. Handbook of Speech Pathology and Audiology, Travis, L. E., (Ed.). New York: Appleton-Century Crofts.

11. Stevens, K. N. (1971): Airflow and turbulence noise for fricative and stop consonants: static considerationsi. J. Acoust. Soc. Amer. 50, 1180 1192. 
12. Stevens, K. N. (n.d.): Acoustic correlates of place of articulation for stop and fricative consonants. Quarterly Progress Report No. 89, Research Laboratory of Electronics, Massachusetts Institute of Technology. 199-205.

13. Van Riper, C. and Irwin, J. V. (1958): Voice and Articulation. Pitman Medical Publishing Co., London.

\section{HEARIMG ARD CENTRE}

S.A. (PTY) LTD

for

HEARING AIDS - Widest range of world-renowned makes

AUDIOMETERS - Wide range of screening - portable diagnostic - clinical - automatic and research models

SILENT CABINS - Single- and double-wall cabins in all sizes. Ventilation - one-way glass - and many other features

AUDITORY TRAINERS - TRANSPOSING APPARATUS - ARTICULATION AMPLIFIERS - GROUP TRAINING EQUIPMENT - SPEECH REPRODUCER - DELAYED SPEECH REPRODUCER PEEP SHOW ACCESSORIES - VISIBLE SPEECH APPARATUS - SOUND-LEVEL METERS PLUS OUR COMPREHENSIVE SERVICE THROUGHOUT THE COUNTRY

ALSO MANUFACTUREAS OF AUDIOMETRIC AND SPEECH TRAINING EOUIPMENT

Head Office: 212 Marley Chambers, Corner Jeppe and Kruis Streets, JOHANNESBURG.

Telephones: $37-2643 / 4 / 5$ P.O. BOX 2269, Johannesburg 2000 Telegraphic Address: BONÁvOX 


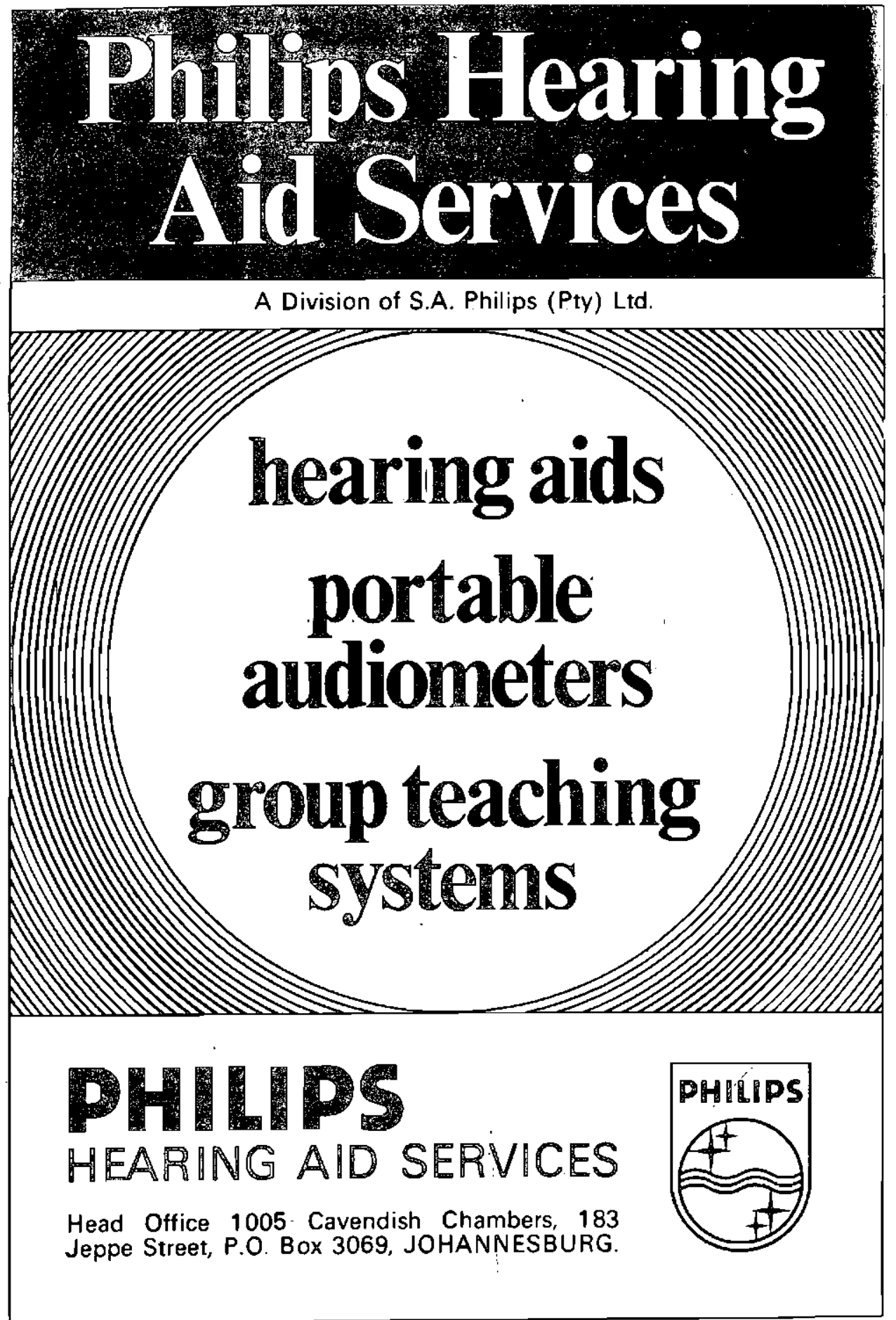

(ivi) 44923 